\title{
DIGITAL MARKETING RAGAM BUDAYA DAN WISATA KABUPATEN JOMBANG BERBASIS ANDROID
}

\author{
Siti Sufaidah*, Munawarah**, Badriyatul Muawanah*** Novia Anggraeni**** \\ * Prodi Sistem Informasi Fakultas Tehnologi Informasi Unwaha \\ ** Prodi Sistem Informasi Fakultas Tehnologi Informasi Unwaha \\ *** Prodi Informatika Fakultas Tehnologi Informasi Unwaha \\ **** Prodi Informatika Fakultas Tehnologi Informasi Unwaha
}

Correspondence Author: idasufaidah@unwaha.ac.id

\begin{tabular}{|c|c|}
\hline Info Artikel : & ABSTRACT \\
\hline \multirow[t]{2}{*}{$\begin{array}{l}\text { Se jarah Artikel : } \\
\text { Menerima : } \\
29 \text { Agust } 2020 \\
\text { Revisi : } \\
\text { 15 Sept } 2020 \\
\text { Diterima : } \\
\text { 10 Okt } 2020 \\
\text { Online : } \\
23 \text { Okt } 2020 \\
\text { Keyword : } \\
\text { Digital } \\
\text { Marekting, } \\
\text { tourism, culture, } \\
\text { Android }\end{array}$} & $\begin{array}{l}\text { Cultural diversity and tourism can be used as tourist objects to be visited by } \\
\text { tourists. This cultural tourism is an activity that includes cultural peculiarities } \\
\text { and uniqueness, it can all be in the form of arts, traditional ceremonies, as } \\
\text { well as interesting works of local art. The development of technology that is } \\
\text { now growing rapidly is very supportive of digital-based tourism and culture } \\
\text { marketing, because it makes it easy for us to get information, one of which is } \\
\text { with an Android-based application. The Android Application of Cultural Diversity } \\
\text { and Tourism in Jombang Regency is very helpful in making it easier for people to find } \\
\text { out about various kinds of tourism and culture in Jombang by optimizing smartphones } \\
\text { that are generally owned by the general public. Application of cultural and tourism } \\
\text { diversity in Jombang Regency has several features / menus, namely Tourist Locations, } \\
\text { about Culture, Jombang Profiles, Jombang Icons, Featured Products and How to Use }\end{array}$ \\
\hline & INTISARI \\
\hline $\begin{array}{l}\text { Kata Kunci : } \\
\text { Digital } \\
\text { Marekting, } \\
\text { Wisata, Budaya, } \\
\text { Android }\end{array}$ & $\begin{array}{l}\text { Keanekaragaman budaya dan wisata bisa dijadikan objek wisata untuk bisa } \\
\text { dikunjungi oleh para wisatawan. Wisata budaya ini merupakan kegiatan yang } \\
\text { mencakup kekhasan dan keunikan budaya, itu semua bisa berupa kesenian, } \\
\text { upacara adat, maupun hasil karya seni masyarakat setempat yang menarik. } \\
\text { Perkembangan teknologi yang sekarang semakin berkembang pesat sangat } \\
\text { mendukung Pemasaran ragam wisata dan budaya berbasis digital (digital } \\
\text { marketing), dikarenakan membuat kita mudah untuk mendapatkan informasi } \\
\text { salah satunya yaitu dengan aplikasi berbasis android. } \\
\text { Aplikasi Android Ragam Budaya dan Wisata di Kabupaten Jombang sangat } \\
\text { membantu memudahkan masyarakat untuk mengetahui berbagai ragam } \\
\text { wisata dan budaya di Jombang dengan mengoptimalkan smartphone yang rata } \\
\text { - rata sudah dimiliki oleh masyarakat umum. Aplikasi Ragam budaya dan } \\
\text { wisata di Kabupaten Jombang memiliki beberapa fitur/menu yaitu Lokasi } \\
\text { Wisata, tentang Budaya, Profil Jombang, Icon Jombang, Produk Unggulan } \\
\text { dan Cara penggunaan. }\end{array}$ \\
\hline
\end{tabular}




\section{PENDAHULUAN}

Jombang merupakan kota yang memiliki banyak ragam budaya dan wisata, banyak wisatawan asing atau lokal yang kurang tahu tentang budaya dan wisata yang berada di kota Jombang. Agar budaya Indonesia khususnya di daerah Jombang harus tetap dilestarikan karena selain memiliki bentuk yang unik yang bisa menarik perhatian wisatawan luar, ragam budaya maupun destinasi wisata juga merupakan salah satu bentuk warisan budaya yang bisa diwariskan kepada anak cucu kita. Ini merupakan sebagian kecil dari beberapa kasus yang ada di Indonesia mengenai kurangnya perhatian masyarakat dalam melestarikan salah satu ragam budaya serta destinasi wisatanya.

Keanekaragaman budaya dan wisata bisa dijadikan objek wisata untuk bisa dikunjungi oleh para wisatawan. Wisata budaya ini merupakan kegiatan yang mencakup kekhasan dan keunikan budaya, itu semua bisa berupa kesenian, upacara adat, maupun hasil karya seni masyarakat setempat yang menarik

Perkembangan teknologi yang sekarang semakin berkembang pesat sangat mendukung Pemasaran ragam wisata dan budaya berbasis digital (digital marketing), dikarenakan membuat kita mudah untuk mendapatkan informasi salah satunya yaitu dengan aplikasi berbasis android. Android merupakan salah satu sistem operasi bebasis linux yang kebanyakan diterapkan di mobile smartphone dan PC tablet. Secara umum android merupakan platform yang terbuka (open source) bebas bagi para pengembang untuk menciptakan aplikasi mereka sendiri sesuai keinginan mereka.

\section{METODE PENELITIAN}

2.1 Tempat Penelitian

Penelitian ini dilakukan di Kabupaten Jombang Jawa Timur dengan data yang diperoleh dari Dinas Pariwisata Kabupaten Jombang dan media elektronik dari tahun 2016-2020. Dengan data terdiri dari Ragam Wisata, Budaya daerah, produk unggulan dan icon kota jombang.

2.2 Rancangan Sistem

Usecase Diagram merupakan konstruksi untuk mendeskripsikan hubungan-hubungan yang terjadi antar aktor dengan aktivitas yang terdapat pada aplikasi. Sasaran permodelan usecase diantaranya adalah mendefinisikan kebutuhan fungsional dan operasional sistem dengan mendefinisikan skenario penggunaan sistem yang akan dibangun. Dari hasil analisis aplikasi yang ada maka usecase diagram dapat di lihat pada Gambar 2.1, usecase bertujuan untuk mendeskripsikan usecase yang digunakan dengan penjelasan yang singkat namun mampu membantu gambaran sistem yang berjalan pada aplikasi mengenai ragam budaya dan wisata berbasis android di kabupaten Jombang.

Dari hasil analisis aplikasi yang ada maka definisi usecase untuk aplikasi di lihat pada gambar 1.

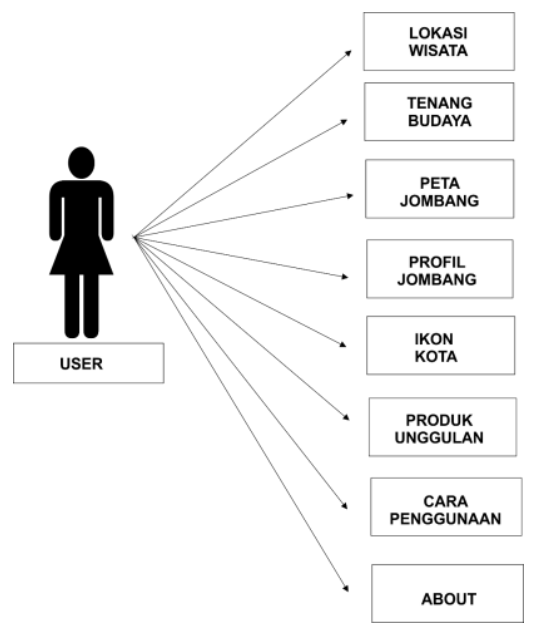

Gambar 1. (Use Case Diagram) 


\section{HASIL DAN ANALISA}

a. Digital Marketing

Digital Marketing merupakan strategi pemasaran yang memanfaatkan tehnologi informasi yang semakin berkembang (Ryan, 2014:4). Hal yang menjadi penentu digital marketing dalam keberhasilan implementasi salah satunya adalah Digital Marketing memberikan kenyamanan untuk digunakan pelanggan/pengguna. Ketika seorang pelanggan/pengguna merasa bahwa media yang digunakan adalah nyaman, maka pelanggan akan dapat menggunakannya dengan lebih efektif dan efisien. Hal ini akan membuat pelanggan merasakan kecepatan akses dalam mencari kebutuhan yang diinginkan dan cenderung lebih cepat menemukan.

Dalam penelitian ini, penulis menekankan pada digital marketing ragam budaya dan wisata berbasis android berdasarkan keunggulan yang dimiliki oleh android. Adapun keunggulan dan kekurangan android adalah sebagai berikut kecepatan internert tinggi dilengkapi dengan aplikasi untuk mengakses informasi, dapat digunakan secara mudah dan praktis, tampilan cukup menarik, murah.

b. Wisata dan Budaya di Kabupaten Jombang

Kabupaten Jombang adalah sebuah kabupaten yang terletak di Provinsi Jawa Timur. Kabupaten Jombang memiliki luas wilayah $1.159,50 \mathrm{~km}^{2}$, dan jumlah penduduknya 1.201.557 jiwa (2010), terdiri dari 597.219 laki-laki, dan 604.338 perempuan. Jombang juga dikenal dengan sebutan Kota Santri karena banyaknya pondok pesantren yang berada di Jombang.

Kabupaten Jombang memiliki berbagai keindahan alam dan potensi pariwisata lain yang menarik. Sangat disayangkan, potensi tersebut pada umumnya belum digali, dan tidak memiliki pendukung sarana dan prasarana yang memadai untuk memajukan pariwisata di Kabupaten Jombang, sehingga menunggu adanya investasi untuk menggarapnya. Hal ini sangat penting dan menguntungkan, mengingat posisi Kabupaten Jombang yang bersebelahan dengan daerah tujuan wisata alam Malang di tenggara dan Pacet-TrawasTretes di timur; serta wisata historis (situs Majapahit) Trowulan. Di Jombang memiliki beberapa tempat pariwisatadan budaya yang menarik, yaitu terdiri dari wisata buatan, wisata alam, wisata minat khusus, wisata religi, kerajian tangan dan oleh - oleh/makanan khas jombang.

c. Aplikasi Android Sebagai Digital Marketing Ragam Budaya dan Wisata Kabupaten Jombang.

Tingkat popularitas android dan smartphone menjadi salah satu alasan membangun aplikasi. Aplikasi android diharapkan dapat menyasar pada masyarakat dan calon wisatawan yang akan melakukan kunjungan di Kab. Jombang. Aplikasi ini memuat peta lokasi wisata, budaya, icon kota dan produk unggulan di Kab. Jombang. Halaman utama aplikasi ini menampilkan 8 menu yang memiliki fungsi berbeda.

Salah satu menu yang perlu untuk dipahami adalah menu lokasi wisata, menu ini memberikan gambaran lokasi wisata di Kab. Jombang menggunakan tampilan peta. Sedangkan untuk menyampaikan ragam budaya di Kabupaten Jombang diletakkan pada menu tentang budaya. Beberapa menu yang lain meliputi menu tentang budaya, peta jombang, profil jombang, icon kota, produk unggulan dan cara penggunaan.

Salah satu menu ayng juga patut untuk diperhatikan adalah menu produk unggulan. Pada halaman ini dijelaskan berbagai produk unggulan yang dimiliki oleh kab. Jombang agar para calon wisatawan ataupun orang yang berkunjung ke kab. Jombang dapat memiliki gambaran terkait produk unggulan yang ada di kab. Jombang. Hal ini secara tidak langsung akan membantu proses penjualan ataupun pengenalan produk unggulan yang ada di kab. Jombang. Berikut ini adalah sebagian tampilan dari aplikasi android sebagaimana pada beberapa gambar di bawah ini : 


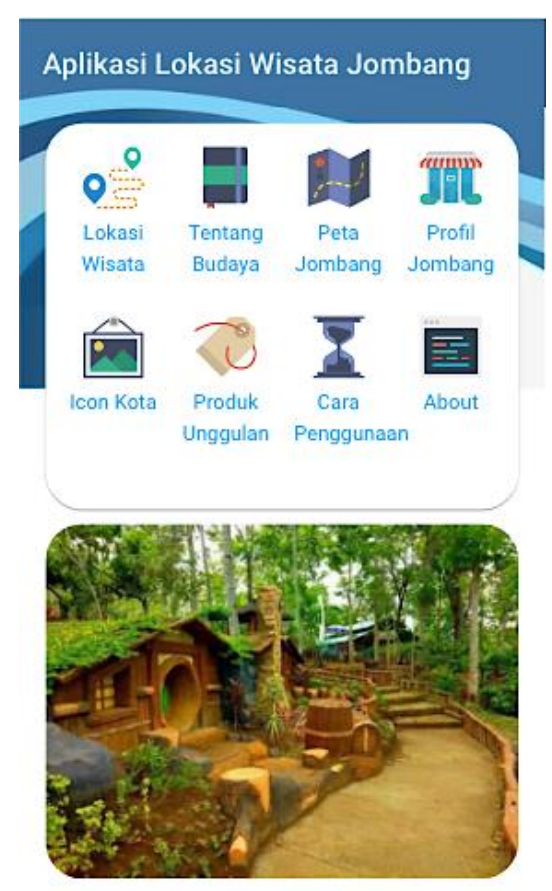

Gambar 2. Halaman utama

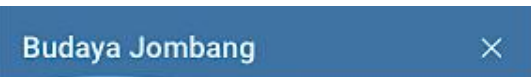

Data Kebudayaan Jombang :

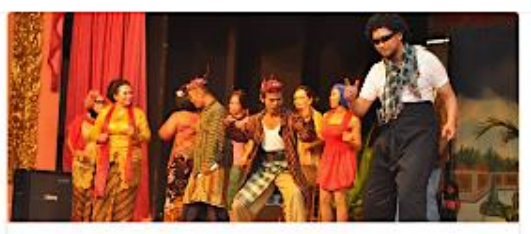

Nama Kebudayaan:

\section{Ludruk}

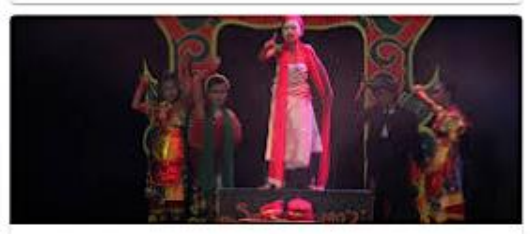

Nama Kebudayaan:

\section{Besut}

Gambar 4. Halaman ragam budaya

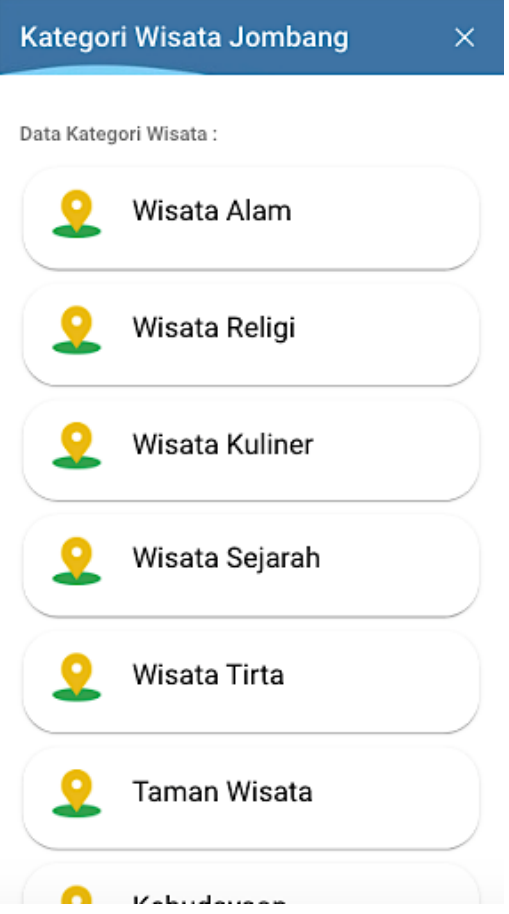

Gambar 3. Halaman kategori wisata Jombang

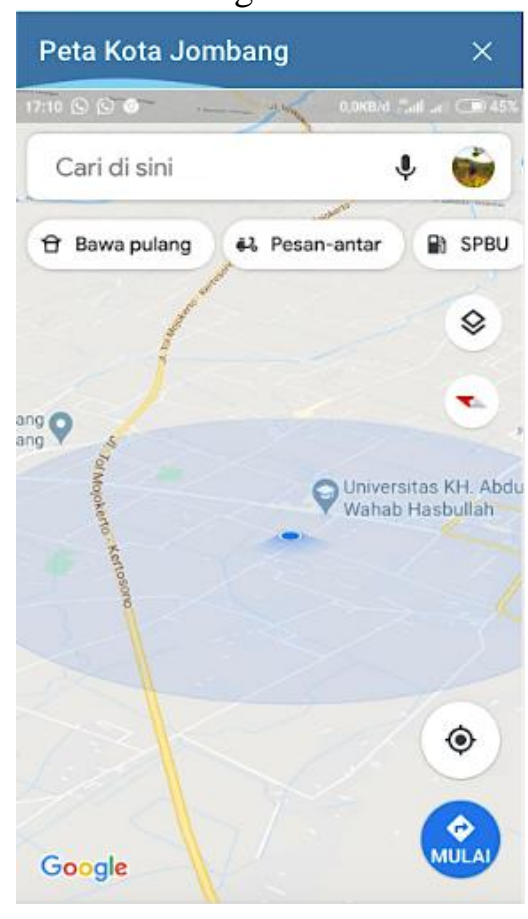

Gambar 5. Peta Kab. Jombang 


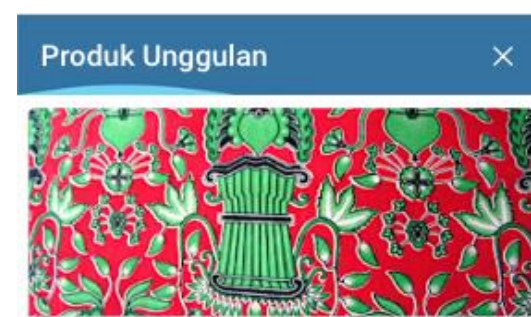

Batik Jombangan Jati Pelem Jombang

Belum banyak yang tahu bahwa Jombang juga punya corak batik khas. Meski sudah dipajang di Museum Batik di Pekalongan, Jawa Tengah

Detail

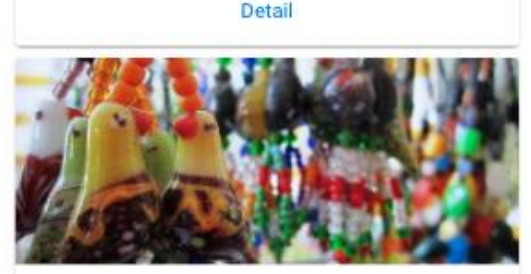

Kerajinan Manik manik kaca Gudo Jombang

Gambar 6.Produk Unggulan Kab. Jombang

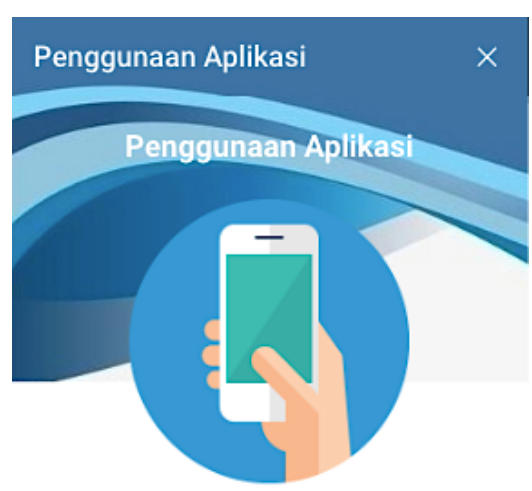

Panduan Penggunaan aplikasi : Dalam aplikasi ini tidak perlu login untuk menggunakan fitur ataupun menu-menu yang ada pada aplikasi. Menu-menu [1. Menu Wisata yang bisa digunakan untuk melihat lokais wisata yang diinginkan yang ada di daerah jombang berdasarkan kategori jenis wisata. 2. Menu Budaya menampilkan beragam budaya yang ada pada kota jombang. 3. Menu Bantuan menampilkan penjelasan aplikasi dan kegunaan menu yang ada. 4. Menu Peta manamnillan nots inmhann dannann titil

Gambar 7. Petunjuk Penggunaan Aplikasi

\section{KESIMPULAN}

Dari penelitian tentang Digital Marketing Ragam Budaya dan wisata berbasis android di Kabupaten Jombang disimpulkan bahwa:

1. Aplikasi Android Ragam Budaya dan Wisata di Kabupaten Jombang sangat membantu memudahkan masyarakat untuk mengetahui berbagai ragam wisata dan budaya di Jombang dengan mengoptimalkan smartphone yang rata - rata sudah dimiliki oleh masyarakat umum,

2. Ragam Budaya dan wisata berbasis Andorid ini juga sangat membantu meningkatkan promo pariwisata Kab. Jombang denagan menggunakan stategi Digital Marketing seiring dengan perkembangan tehnologi 4.0.

3. Aplikasi Ragam budaya dan wisata di Kabupaten Jombang memiliki beberapa fitur/menu yaitu Lokasi Wisata, tentang Budaya, Profil Jombang, Icon Jombang, Produk Unggulan dan Cara penggunaan.

4. Ragam Budaya dan wisata Kabupaten Jombang juga bekerjasama dengan Dinas Pariwisata Kab Jombang

\section{ACKNOWLEDGEMENTS}

Alhamdulillah, penelitian Digital Marketing Ragam Budaya dan wisata berbasis android di Kabupaten Jombang ini di biayai dari Dana Hibah Penelitian Dosen Pemula KemenriktekDikti Tahun 2020. 


\section{DAFTAR PUSTAKA}

Al Bahra Bin Ladjamudin, 2005, Analisis dan Desain Sistem Informasi, Graha Ilmu, Yogyakarta.

Fuan Hasan, 1998, Pendidikan kebudayaan Indonesia, Jakarta.

Hermawan, S.S., 2011, Mudah Membuat Aplikasi Android, Andi Offset, Yogyakarta.

Irawan, H.(2002). 10 Prinsip Kepuasan Pelanggan. Jakarta : PT Elex Media Komputindo.

Kadir, A., 2009, Dasar Perancangan \& Implementasi, Andi Offset, Yogyakarta.

Koentjaraningrat, 1998, Kebudayaan Indonesia, ,Andi Offet, Jakarta.

Narbuko, Cholid dan Ahmadi, Abu, 2002, Metodologi Penelitian Bumi Aksara, Jakarta.

Pressman, R. S. 2010. Software Engineering A Practitioner's Approac (7th ed.), New York : McGraw-Hill.

Priyanta F. 2011, Pemrograman Android Untuk Pemula. Jakarta, Cerdas Pustaka Publisher.

Ryan, D.(2004). Understanding Digital Marketing. Great Britain:Kogan Page Limited.

Safaat, N.H., 2010, Pemrograman Aplikasi Mobile Smartphone dan Tablet PC Berbasis Android, Informatika, Bandung. 